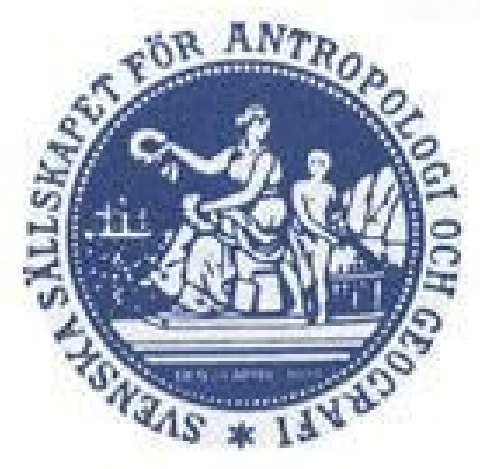

\title{
WILEY
}

Studies of the Frost Problem II

Author(s): Anders Ångström

Source: Geografiska Annaler, Vol. 3 (1921), pp. 278-290

Published by: Wiley on behalf of Swedish Society for Anthropology and Geography

Stable URL: http://www.jstor.org/stable/519436

Accessed: 25-06-2016 17:47 UTC

Your use of the JSTOR archive indicates your acceptance of the Terms \& Conditions of Use, available at

http://about.jstor.org/terms

JSTOR is a not-for-profit service that helps scholars, researchers, and students discover, use, and build upon a wide range of content in a trusted digital archive. We use information technology and tools to increase productivity and facilitate new forms of scholarship. For more information about JSTOR, please contact support@jstor.org.

Swedish Society for Anthropology and Geography, Wiley are collaborating with JSTOR to digitize, preserve and extend access to Geografiska Annaler 


\section{STUDIES OF THE FROST PROBLEM II.}

FORECASTING OF DYNAMICAL CHANGES OF TEMPERATURE.

BY ANDERS ÅNGSTRÖM.

T $\mathrm{n}$ a preceding paper $\mathrm{I}$ have treated a material of records, from which a computation of the average temperature fall during the night as a function of the temperature and humidity was attempted under various conditions in regard to cloudiness. We were able to express the average temperature fall through the relation:

$$
T_{\min }=t_{\mathrm{I}}-C T_{\mathrm{o}}-k \ldots \ldots \ldots \ldots \ldots
$$

where $T_{\min }$ is the minimum temperature of the night, $t_{\mathrm{I}}$ and $T_{\mathrm{o}}$ the reedings of the wet and dry thermometer resp. at 7 h. p. m. and $C$ and $k$ are constants, the latter depending of the cloudiness. The average temperature fall, defined in the named way, comes probably very near to what I will call the »statical cooling", whereby no cold or warm air masses are introduced dynamically neither through vertical nor through horizontal displacements. In predicting the minimum temperature in the named way we can therefore scarcely expect to reach the limit of our possibilities for forecasting in the individual cases, while no regard has been taken to the informations furnished by the synoptic map regarding the temperature distribution and dynamical properties of more extended parts of the atmosphere. In the first part of my treatise I made an attempt to account for these conditions by investigating, how the difference between computed and observed values was dependent of the first derivative of the temperature in regard to time at the hour of the issuing of the forecast. It lays near at hand to expect that a more or less rapid fall of the temperature than the normal during a preceding time, would have a tendency to continue afterwards. An investigation hereof led to practically a negative result.

The latest researches in regard to the constitution of the atmosphere in cyclones and anticyclones have more and more led to an increased realisation of the importance of surfaces of discontinuity. The cold and warm air currents, which seem to be general constituents and important agents in the cyclones, are separated by relatively sharp boundaries, characterized by sudden changes in temperature, humudity, and wind direction. The examination of the synoptic charts giving the conditions round the north European cyclones, have in this point in general supported the ideas put forward by Dove, Bigelow, Margules, Exner, v. Ficker, 
and Bjerknes. For the forecasting, especially of temperature changes, the discovery of the surfaces of discontinuity has an important consequence, which may be formulated in the following way: It is impossible to predict dynamic changes in temperature through local temperature observations alone. First through a study of the synoptic charts, where the approach of cold and warm areas may be studied, we may be able to predict the dynamic changes in temperature.

A forecast regarding the temperature, and here especially the minimum temperature during the night, then includes two predictions equally important: one of the statical, the other of the dynamical fall of temperature to be expected. Considering the difficulty in giving an exact value for the latter, it seems appropriate to imagine the two effects in the first place as independents, assuming:

$$
\Delta t=\Delta t_{s}+\Delta t_{d}
$$

where $\Delta t$ is the predicted temperature fall, and $\Delta t_{s}$ and $\Delta t_{d}$ are the statically and dynamically predicted temperature falls, resp. For the forecast of the minimum temperature resulting from both effects, we obtain:

$$
\mathrm{T}_{\min }=T_{\min }-\Delta t_{d}
$$

where $T_{\min }$ has to be computed according to the formula (I).

Our problem is then reduced to an application of the laws or rules generally used for predicting temperature changes, which are independent of the daily variation of temperature. Such predictions have since long been issued from the meteorological offices and a number of valuable experiences have been gathered. A further investigation with direct application on the problem here at hand, has been attempted by studying the synoptic charts in the cases, where $\Delta t_{d}$ shows positive or negative values. Reference may here be made to the specifications given below regarding the general conditions in the cases, where $\Delta t_{d}$ has had value larger than $\pm 3^{\circ}$ and to the miniature synoptic charts given for some typical extreme cases. In general, when $\Delta t_{d}$ has had a large value and a negative sign, we have been located either in the eastern parts of a high area, which especially occurs in the case of clear to half clear evenings, or in the central or back side parts of the zvarm starboard sector of a cyclone with the High in the west, which especially occurs in the case of cloudy evenings. In the former case the temperature gradient in the direction from which the wind is blowing, seems often to be an indicator on the temperature change to be expected, so that the effect is weakened and some times reversed when the temperature increases, strengthened when it decreases in the direction towards the wind. Examples hereof are presented especially by the evening charts of May 30th, 1915, and April 24th, 1916. 
In the cases where the temperature fall is caused by the approach of a cold or warm area, the difference in temperature between the station and a more westerly situated one, is only seldom an indicator on the temperature changes $\Delta t_{\dot{d}}$. I find in the cases where the station has been situated on the former and starboard side of the path of a cyclone and we consequently have to expect in general the approach of a warm area, that the temperature of Karlstad at 7 h. p. m. is higher than that at Uppsala at the same time in I 8 cases out of 25 , that $\Delta t_{d}$ has a positive sign in 23 cases of 25 , and that in the cases where $\Delta t_{d}$ has had a positive sign the difference Karlstad-Uppsala has been positive in 19 cases out of 23. The average value for the difference in temperature between Karlstad and Uppsala is in the named cases $+0 .{ }^{\circ} 8$ degrees, the average value of $\Delta t_{d}+{ }_{1}^{\circ}{ }^{\circ} 8$. Similarly, when we are situated on the starboard side of the path of a cyclone, but with the centre passing or already passed, we have to expect in general the approach of a colder area. Then $\Delta t_{d}$ has a negative sign in 27 cases out of 34 , but the difference Karlstad-Upsala is negative only in Io cases out of 34 . In the cases where $\Delta t_{d}$ has a negative sign, the latter difference is only negative in 9 cases of 27 .

In general there are four principal cases, where $\Delta t_{d}$ obtains a positive sign. The one is named, when we are on the former but starboard side of a cyclone. Then we have often a half clear or even clear sky, with sometimes a low relative humidity; the cooling to be expected from the statical conditions is then large. But the dynamical situation implies a less rapid cooling from double reasons. First the approach of the warm area of the cyclone is to be expected. Secondly an increase of the cloudiness, often combined with the beginning of rain, is also to be foreseen. In regard to the approach of the so called »warm sector» of a cyclone, it must be pointed out that this sector not necessarily needs to appear warm at ground. Still its arrival causes generally a rise, its disappearing a fall in temperature. Such cases are presented for instance by 21 May 1916, and io May I915. The effective heat content of the lower parts of the warm air current may often have been used up for the compensation of a former depression in temperature near the ground; then the warm area is not noticeable through the values of the temperature near the ground, but more through the temperature changes which it produces. In general it seems to have foundation in the material at hand to start from the idea, that every cyclone has a »warm sector» which produces rise in temperature, but which not always is warn at the ground stations.

A second case where $\Delta t_{d}$ becomes positive seems often to occur in the central parts of a slowly moving cyclone, where constant cloudiness and often rain prevails. I am not sure that the value found for $\Delta t_{d}$ in these cases has always a purely dynamical cause. The ground, wet from rain, has then a high temperature con- 


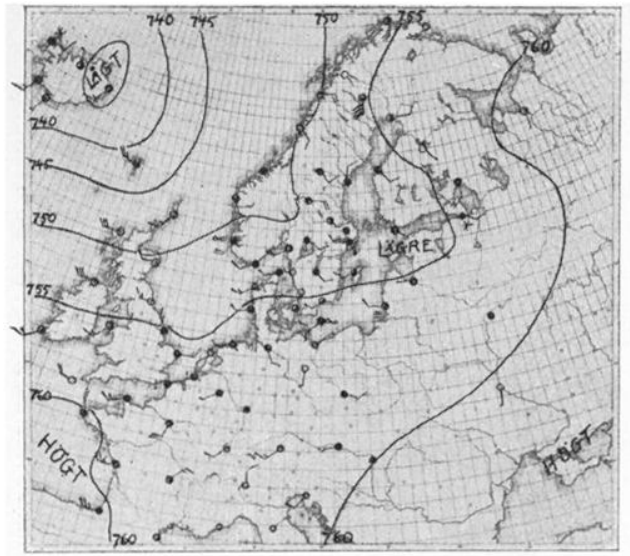

April 5, 19r5. 7 h. p. m.

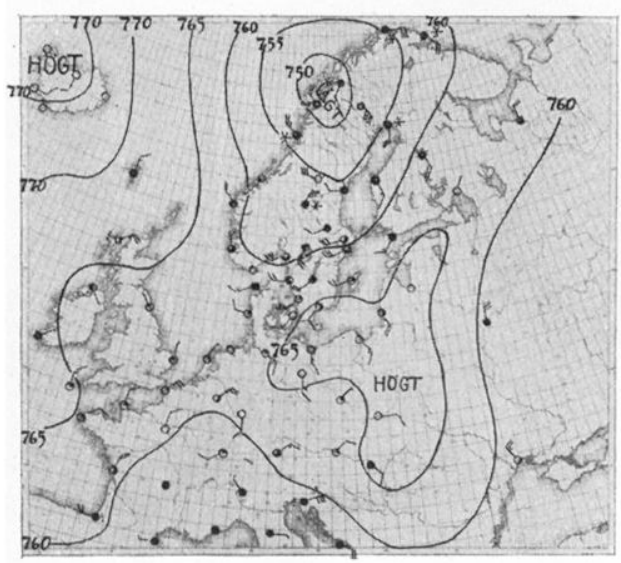

May Ir, I9r5. 8 h. a. m.

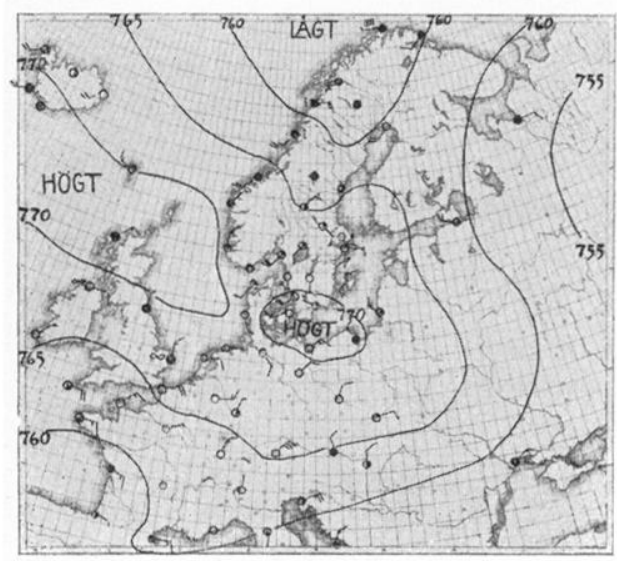

May 25, r9r5. 8 h. a. m.

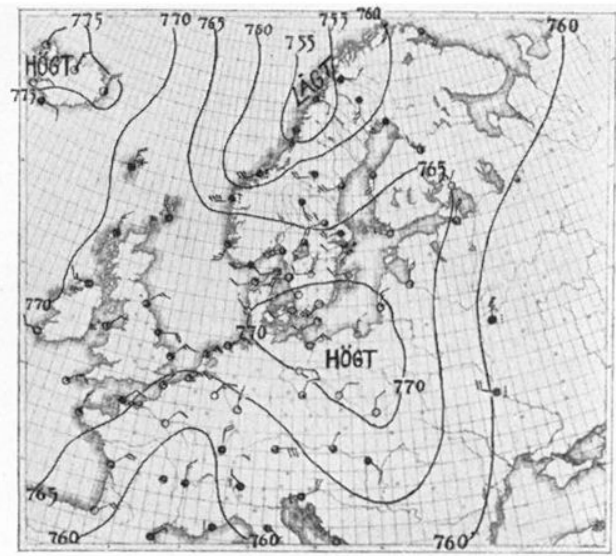

May ro, rgr5. 7 h. p. m.

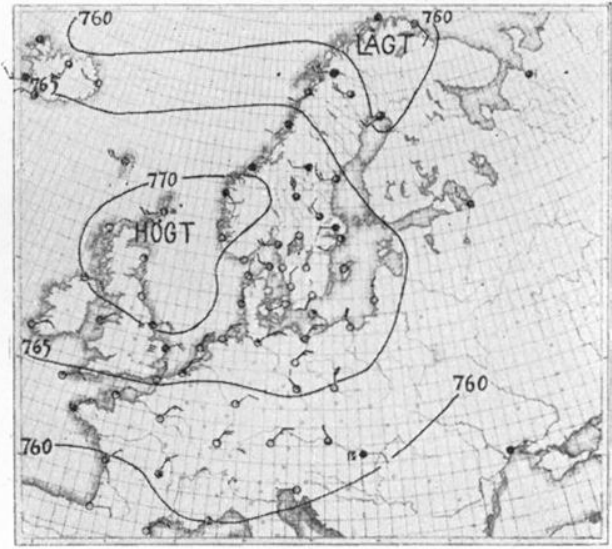

May 24, r9r5. 7 h. p. m.

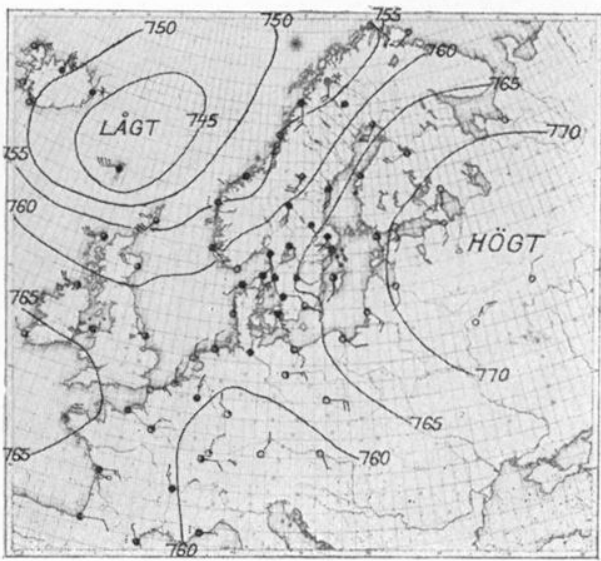

April 8, rgi6. 7 h. p. m.

Fig. I. Dynamical rise in temperature. $\Delta t>3^{\circ} \mathrm{C}$.

I8 a Geografiska Annaler I9zI. 


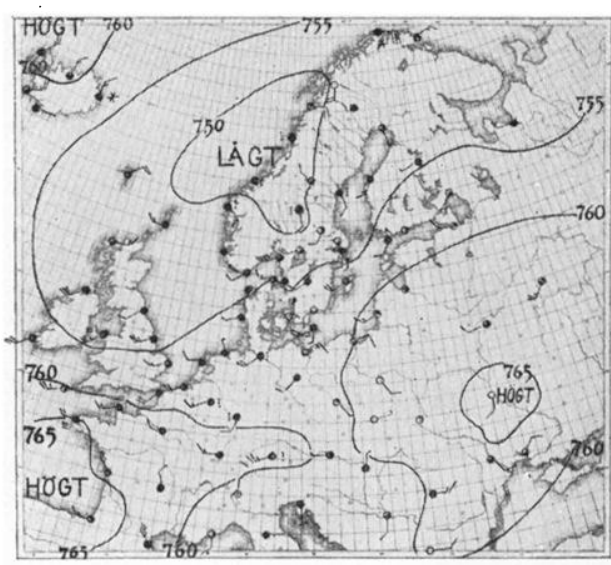

May 14, r9x6. 7 h. p. m.

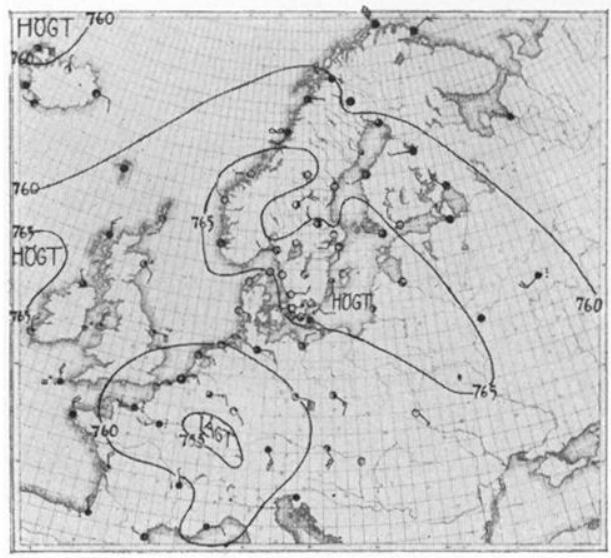

May 28, I9r 7.7 h. p. m.

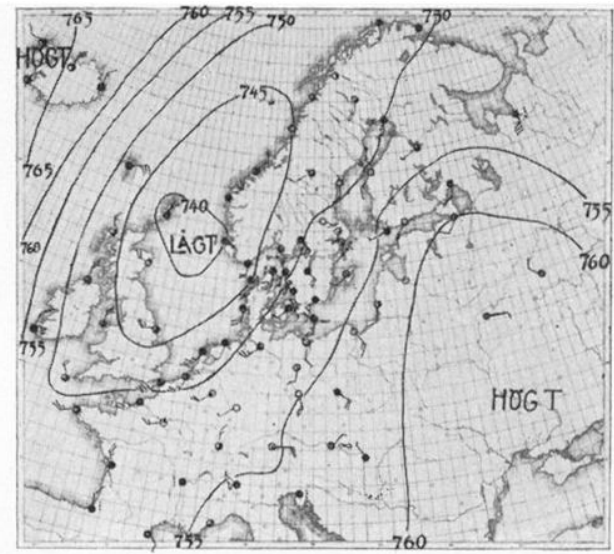

April $x_{4}, x_{917} 7$ h. p. m.

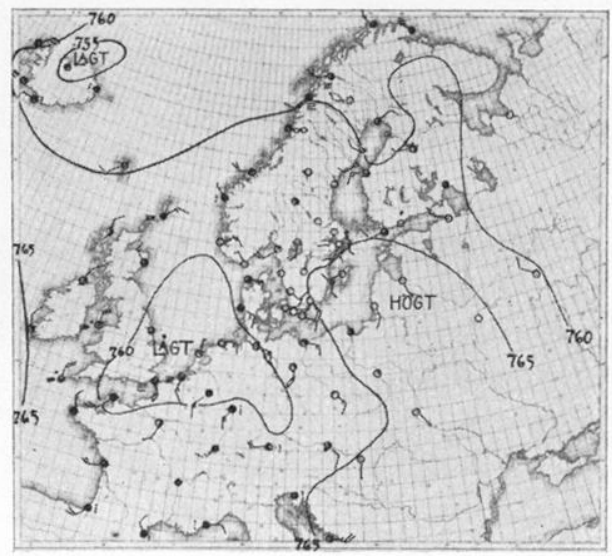

May 29, I9r7. 8 h. a. m.

Fig. I (cont.). Dynamical rise in temperature. $\Delta t>3^{\circ} \mathrm{C}$.

ducting power, which influences the statical cooling in the direction to make it less rapid. As we have, in the expression given for the statical cooling, taken no regard to the properties of the ground itself, some changes in its properties give us an apparent dynamic effect, which influences the value of $\Delta t_{d}$. It may here be enough to state that such effects occur and that they enter into our value of $\Delta t_{d}$ by definition. They must be considered when we try to fix a value for $\Delta t_{d}$. A ground, humid from rain, or conditions, which have caused a high temperature of deeper layers of the soil, shows a tendency to give us a decreased cooling effect during the night and vice versa.

Finally there are two more very important cases, easily defined, where $\Delta t_{d}$ 
becomes positive. The first one occurs, when we are situated in a low pressure area, but in a higher intermediate region between two near to one another located secondary Lows. During the period considered 8 such situations, very clearly developed, have presented themselves, namely on April 9, 1915, April 6, I0, I2, I3 and 18, 1917, May 3 and 10, 1916. Of these cases only April 9, 1915, shows no dynamic change of temperature neither in the one nor in the other direction; the other seven cases show all a decided rise of temperature, the average dynamic rise being equal to $\mathrm{r}^{\circ}{ }_{4}$ between 7 h. p. m. and the time of the minimum of the following night. Here we have undoubtedly to do with an adiabatic heating of descending air masses.

Especial attention must be attached to the last and fourth case, which is clearly demonstrated by the maps of May 10 and 11,1915 . It is the situation, where we are located in the intermediate region between a. High and a Low, the former situated in the South, the latter in the North. Then we are in the warm area of the cyclone, and it lays near at hand to expect a dynamical cooling, as a consequence of its disappearing. But an investigation of the case shows that on account of the southwestern winds of the back-side of the anticyclone, the warm area of the cyclone, must not only be intensified, but is also shifted to the west, the region of the maximum temperature of the cyclone not being in this case situated at the south but at the west-south-west of it. The warm south-western winds of this region, resulting from the conbined effect of as well the Low as the High, I think explains fully the pronounced rise in temperature, shown in these situations. O. V. Johansson assumes that the high temperature in similar cases is a consequence of an adiabatic warming of vertically displaced air masses. Such displacements may naturally occur especially near the high center, but in general I think the horizontal displacements constitute the principal cause of the observed effect. The period investigated shows ro cases of a Low in the north, a High in the south. Of these cases 8 show a dynamic rise in temperature during the night, only 2 show a slight dynamic cooling. The average rise in temperature is $1 .{ }^{\circ} 3$.

Between this situation just discussed, and the one where we are situated at the south of the Low, with the High in the west, a situation characterized by a dynamical cooling during the following 8 hours, a number of intermediate cases occur, which must be treated with special experience and judgement in forecasting. They have all in common that the Low is situated in the north, the High between the west and the south. Often, as in the situation shown by the maps of May 24 and 25, a pronounced dynamical rise in temperature $\left(+3 .{ }^{\circ} 7\right)$ has occurred. Other cases, as for instance May 30, 1915, show under similar conditions a heavy fall in temperature $\left(-3 \cdot{ }^{\circ}\right)$. In such instances a close consideration of a number of influences is necessary. 
In some cases a positive sign for $\Delta t_{d}$ has occurred in or in the neighbourhood of high pressure areas, especially at their western side, as for instance in the case presented by May 28 and 29, 1917. The former date shows a local minimum formed in the high centre and causing warm air from the south to be soaked in. In the latter case we are on the back side of the high centre with strong southerly winds prevailing. The temperature shows an increase in the direction towards the wind.

The discussion presented above regarding the conditions favouring a negative sign of $\Delta t_{d}$, has given results, which are in general agreement with those reached by Hamberg from a much more extended material regarding the conditions under which frost is liable to occur. Through the separation of the effects $\Delta t_{s}$ and $\Delta t_{d}$ it seems however possible to reach, even from a limited material, conclusions regarding the pure effects of the dynamical situation.

Hamberg comes regarding the frequency of frost in Sweden in its relation to synoptic weather to the conclusion that in general it is large in two cases, namely on the back side of Lows, where the wind is $\mathrm{W}-\mathrm{N}-\mathrm{O}$, and further in the High centres. Frost occurs, however, never at the former side of a Low and very seldom when the High is situated in S-SO. (Cirkulär N:o 5 from Upsala Observatorium etc. Upsala 1874 , pag. 4.) According to the views expressed in the present paper, we must ascribe the frost occurring at the back side of Lows to the effect of as well a high dynamical as also a high statical cooling, the former caused by the cold northern winds and the disappearing of the warm sector, the latter due to clearing and to decreasing relative humidity. The frost occurring in the western and central parts of a high centre is generally due to a high statical cooling caused by a high nocturnal radiation; ${ }^{\mathrm{I}}$ hereto comes in the eastern parts of the Highs a dynamical cooling due to the northern winds, which generally carry cold airmasses. In the spring time a dynamical cooling is caused also, in the eastern parts of Sweden, by the eastern winds from the Bothnic in connection with the High centres, a fact, which is very evident from a number of cases.

If the results of the present investigation are combined with the negative result of the attempt mentioned in my former note, to predict a dynamic rise or fall in temperature from a more or less rapid rise or fall than normal during a passed time at the station itself, we may consider the present investigation as a support of the ideas especially strongly advanced by Bjerknes regarding the oc. currence of discontinuities closely connected to the cyclones. Were the temperature changes continuous, then we would expect to be able to predict the changes, at least in the near future, through a perfect knowledge of the present temperature and its derivatives in regard to time. When this, as in the present investi-

\footnotetext{
${ }_{1}^{1}$ Compare A. Angström: Nocturnal radiation and synoptic weather. Geogr. Annaler, H. 1/2 I 921 .
} 


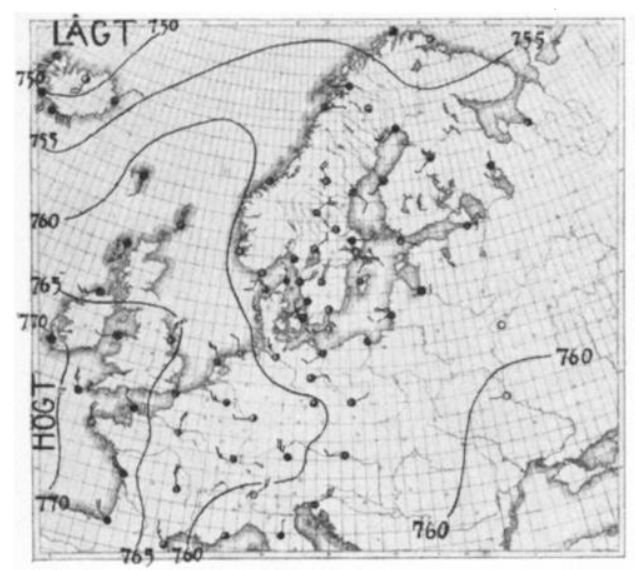

April ro, 19r5. 7 h. p. m.

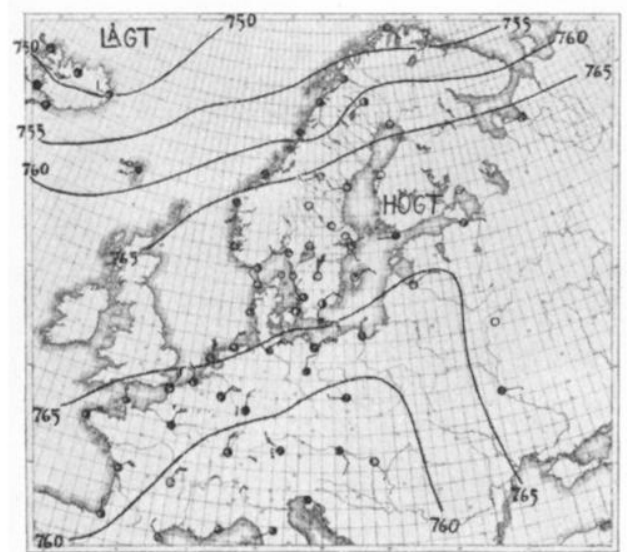

April 23, 1915. 7 h. p. m.

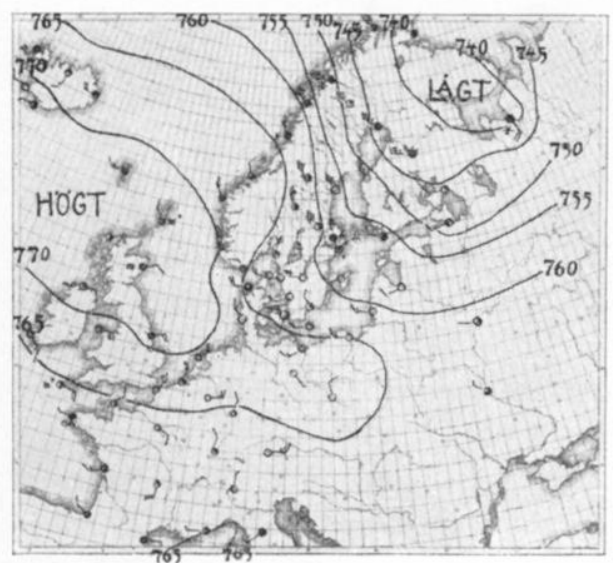

April 28, 19x5. 7 h. p, m.

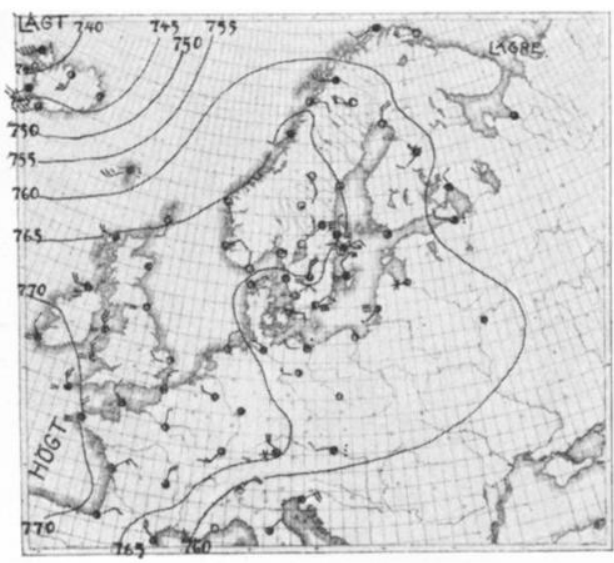

April II, 1915. 8 h. a. m.

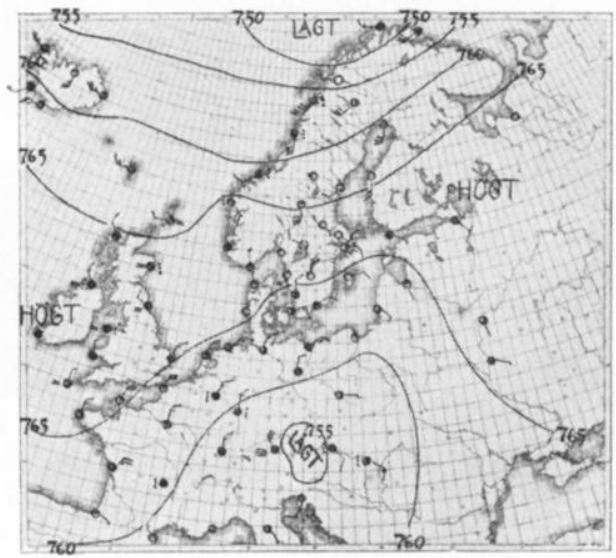

April 24, 1915. 8 h. a m.

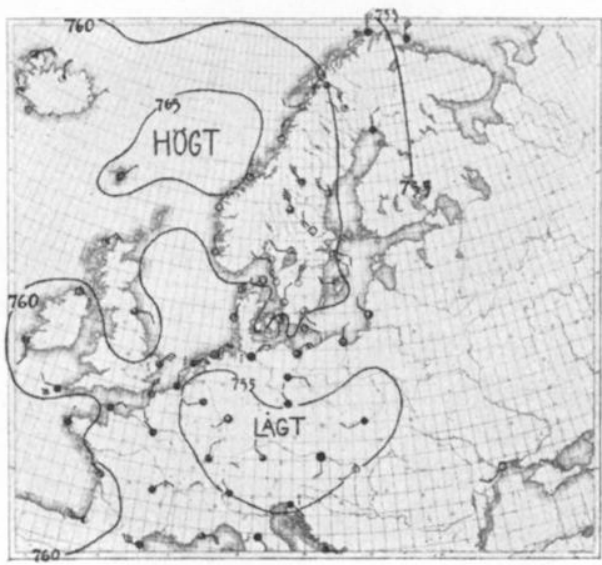

May 18, r9x 5 h. p. m.

Fig. 2. Dynamical fall in temperature. $A t_{d}<-3^{\circ} \mathrm{C}$. 


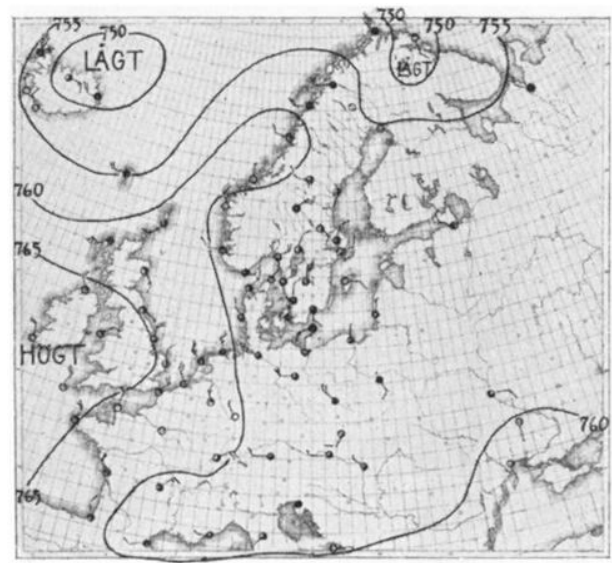

May 30, I9r5. 7 h. p. m.

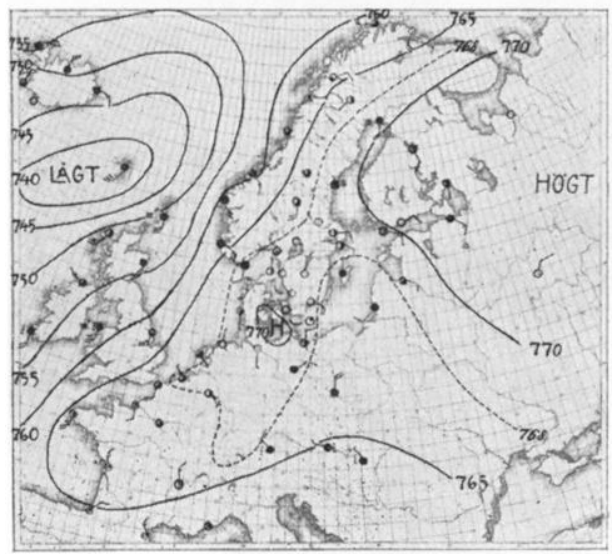

April 24, r9x6. 7 h. p. m.

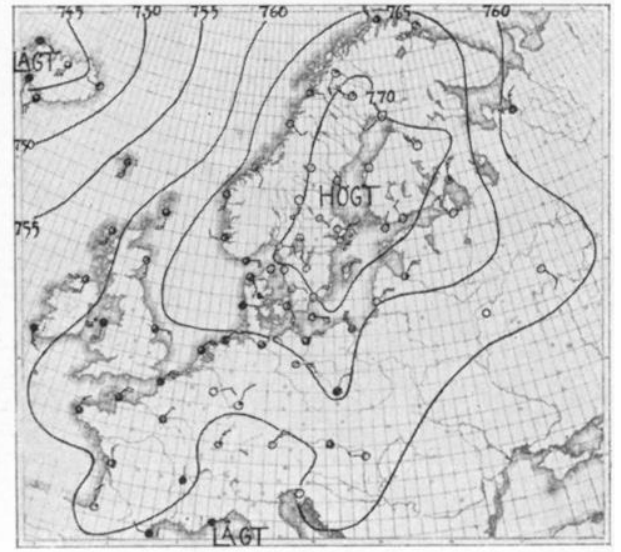

April 6, x9r6. 7 h. p. m.

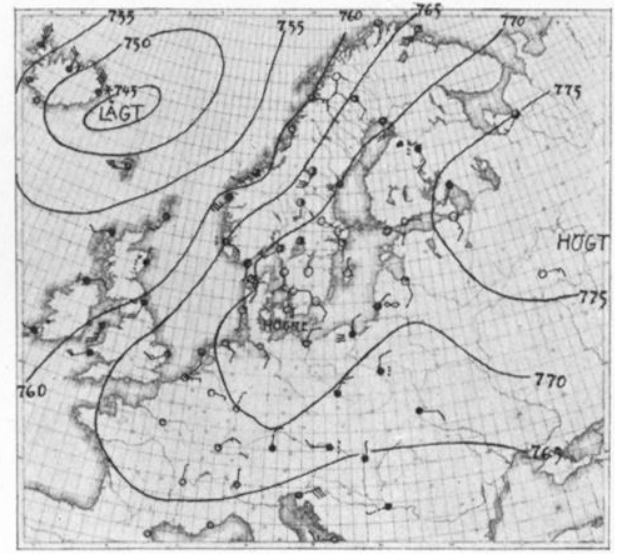

April 25, r9r6. 8 h. p. m.

Fig. 2 (cont.). Dynamical fall in temperature. $\Lambda t_{d}<-3^{\circ} \mathrm{C}$.

gation, appears to be practically impossible in regard to the dynamic changes, we must conclude that these changes are not in general of a continuous character. As in many fields of natural research, we are also in dynamic meteorology passing from the believe in the continuity of natural phenomena to an opposite view, where discontinuity prevails.

Finally the necessity must be pointed out of studying the dynamic changes in temperature, as free from the perturbances caused by the daily period in temperature, and the influence of radiation. Such attempts have often been made 


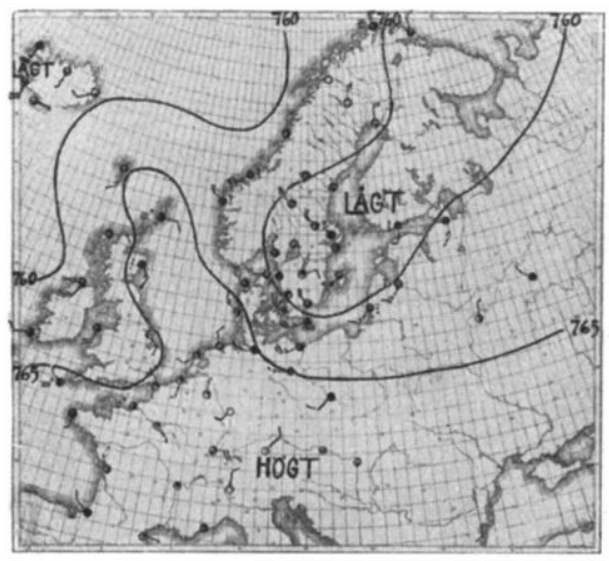

May 2x, 19x6. 7 h. p. m.

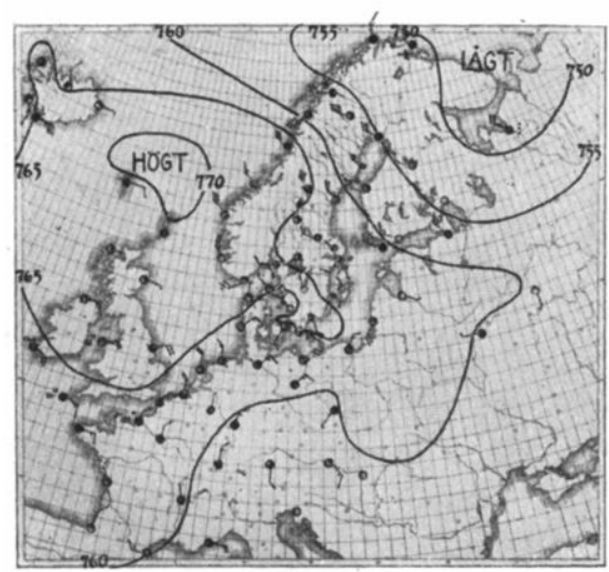

May 16, 1917. 7 h. p. m.

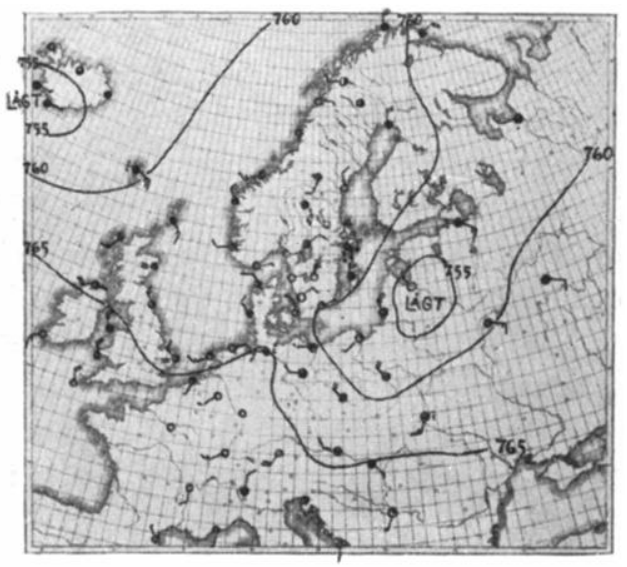

May 22, 1916. 8 h. a. m.

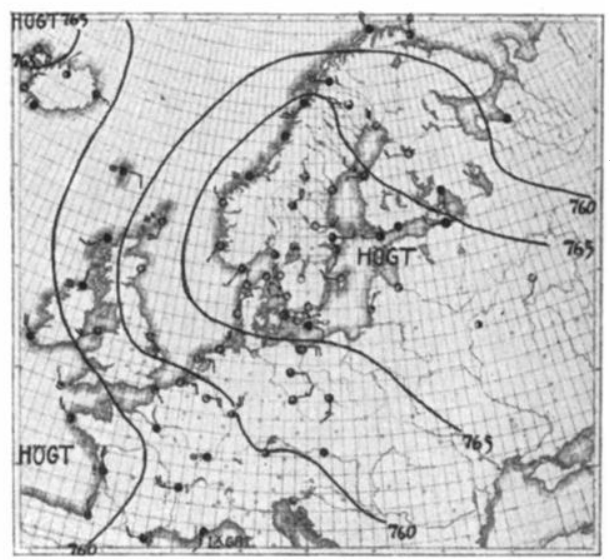

May 27, 1917. 7 h. p. m.

Fig. 2 (cont.). Dynamical fall in temperature. $\Delta t_{d}<-3^{\circ} \mathrm{C}$.

by considering the temperature corresponding to the same hour of the day, as for instance $8 \mathrm{a} . \mathrm{m}$. or $7 \mathrm{p}$. m. The disadvantage hereby lies in the fact that the characteristic details of the changes in most cases disappear, when a time interval of as much as $24 \mathrm{~h}$. is considered. The present investigation is founded upon a study of the temperature changes during time intervals, which in general are shorter than 8 hours, and it may therefore, in spite of the limited material upon which it is founded, add some valuable data to the knowledge of dynamic changes in temperature.

When a perfect knowledge of the influence of humidity, cloudiness and height 
of the sun upon the temperature at a number of stations in a future will be known, we will be able to draw the dynamic isoalloterms for time intervalls of desired shortness and thus facilitate in considerable degree the forecasting of dynamic changes in temperature. As long as, however, the barometric pressure is the only meteorological element, which is measured in a way excluding serious criticism, the forecasting of changes in temperature must necessarily be closely connected to a study of the distribution of pressure and the direction of winds.

Statens Meteorologisk-Hydrografiska Anstalt, March I92r. 


\section{Clear evenings $(000)$.}

I) $\Delta t_{d}<-3^{\circ} \mathrm{C}$ (dynamic fall of temperature).

April 23, 1915: High pressure area over the North sea, southern Scandinavia and the Baltic. (O.) Calm. $\Delta t_{d}=-3^{\circ} .8$.

April 6, 1916: High pressure area over eastern Scandinavia. (O.) Wind E. $\Delta t_{d}=-3^{\circ} .6$.

April 24, r916: High pressure area over eastern Scandinavia. o. Wind E. $\Delta t_{t l}=$ $=-3^{\circ} \cdot 9$.

May 30, I916: Pressure high in the North, extending over western Norway and Götaland. A small secondary depression in the High over eastern Svea. land and southern Norrland. Former side of high area. C. Wind SW. $\Delta t_{d}=-3^{\circ} \cdot 7$.

2) $\Delta t_{d}+3^{\circ} \mathrm{C}$ (dynamic rise of temperature).

May 14, I916: Low pressure area over Middle Norway. High in southern Russia. c. Wind SSE. Temperature difference Karlstad-Upsala $=+2^{\circ} .0$; $\Delta t_{d}=+4^{\circ} \cdot \mathrm{I}$.

April r 4, I917: Low pressure over the northern North Sea. Higher in Russia. o. Wind S. Temperature difference Karlstad-Upsala $=+\mathrm{I}^{\circ} .0$; $\Delta t_{d}=+3^{\circ} \cdot 2$.

May 2, 1917: Low pressure aree over Finlandia and also in the North-West of Scotland. $O$ Wind NW. Temp. diff. Karlstad-Upsala $=+2^{\circ} . \circ$; $\Delta t_{d}=+3^{\circ} \cdot 3$.

May 28, 1917: High pressure area over southern Scandinavia. A secondary depression with falling pressure formed in the western Svealand. Back side of high area. Warm air soaked in from the South. O. Wind SSW. $\Delta t_{d}=+4^{\circ} .8$.

May 29, 1917: Pressure low in the North, high on the Baltic Sea. Back side of high area. Pressure falling rapidly in South Sweden. Warm air soaked in from the South. 0 . Wind SSW. $\Delta t_{i}=+6^{\circ} .6$.

\section{Cloudy evenings $(\bullet)$ ).}

1) $\Delta t_{d}<-3^{\circ} \mathrm{C}$ (dynamic fall in temperature).

April 10, 1915: Pressure low in the North, high on the North Sea. Former side of high area. $\bullet$. Wind E. $\Delta t_{d}=-4^{\circ}$.o.

April 28, 1915: Pressure low at Kola, high on the North Sea. Former side of high area. - :. Wind NNW 8. $\Delta t_{d}=-4^{\circ} .8$.

May 13, 1915: Low area over northern Scandinavia, and on the British Channel, high over Iceland. Low southern sector. $\bullet$. Wind NNW. Diff. Karlstad-Upsala $=-2^{\circ} .0 ; \Delta t_{d}=-5^{\circ} \cdot 9$.

May 30, I915: Pressure low at Cap North and over Iceland, high over Great Britain; rising. o. Wind $\mathrm{N}$. $\Delta t_{d}=-3^{\circ} \cdot 4$.

May 27, 1916: High pressure area over Scandinavia. $\circlearrowleft$. Wind S. High temperature in eastern Svealand seems purely local. (Upsala $+16^{\circ} .0$; Karlstad $+4^{\circ} .0$; Visby $+9^{\circ} .0$; Härnösand $+4^{\circ}$. .o.) $\Delta t_{d}=-4^{\circ}$.г .

19 Geografiska Annaler 1921 . 
May 5, I916: Pressure low in the North of France, high over Iceland. o. Wind NE. Heavy temperature fall, probably caused by introduction of cold air from the North and by clearing. (Upsala + I ${ }^{\circ} .0$; Härnösand $+2^{\circ}$.o.) $\Delta t_{d}=-3^{\circ} \cdot 2$.

May 2I, I9I6: Central part of low pressure area. ๑. Wind NW. Disappearing "warm sector». This case shows »warm sector» not to be necessarily warm at the surface of the earth, but yet causing rise in temperature. (Upsala $+9^{\circ} .0$, Karlstad $+13^{\circ} .0$; Skagen $+\mathrm{I} 3^{\circ} .0$.) $\Delta t_{d}=-4^{\circ} \cdot 9$.

April 5, 1917: Pressure low over Finlandia, and at the Orkney islands, high in the South. Temperature fall caused by snow and local clearing in the night. o. Wind WNW. $\Delta t_{d}=-5^{\circ} \cdot \mathrm{I}$.

May 16, I917: Low pressure area over the White Sea; high approaching area on the North Sea. Q. Calm. Temperature fall caused by dominating northern winds and clearing. $\Delta t_{d}=-3^{\circ} \cdot 6$.

May I9, I9I7: Secondary low area disappearing. $\bullet$ Wind E. Fall in temperature through northern cold winds and clearing. $\Delta t_{d}=-4^{\circ} \cdot \circ$.

May 27, I9I7: Central high area. O. Wind E. Fall in temp. through northern winds and clearing. $\Delta t_{d}=-3^{\circ} \cdot 5$.

2) $\Delta t_{d}>+3^{\circ} \mathrm{C}$ (dynamic rise in temperature).

April 5, I9 5: At South of approaching Low. O. Calm. Temperature difference Karlstad-Upsala $+\mathrm{I}^{\circ} \cdot 7 \cdot \Delta t_{d}=+3^{\circ} \cdot \mathrm{r}$.

May IO, I915: At South of approaching Low. Pressure rapidly falling. e. WSW. Temperature difference Karlstad-Upsala $\pm 0^{\circ} . \circ$. Case of »warm sector» causing rise in temperature, without being warm at ground. $\Delta t_{d}=+3^{\circ} . \circ$.

May 24, 19I5: Low pressure in the North, extending from Cap North to Iceland, high on the North Sea. Case interesting, while generally a dynamic fall, caused by northern winds and clearing, would have been predicted, had not the pressure been falling, showing the approach of Low from the North. Rain during night. ๑. Wind W. $\Delta t_{d}=$ $+3^{\circ} \cdot 3$.

May 28, I9 I 5: Area of low pressure over eastern Europe, extending over the middle parts of Scandinavia. Pressure falling rapidly over Svealand, showing the depression to be extended more and more westward. $\bullet$. Wind SW. $\Delta t_{d}=+3^{\circ}$.o.

April 8, r9i6: Pressure high in the East, low between Iceland and Scandinavia; depression going eastward. •. Wind S. Temperature diff. Karlstad-Upsala $+\mathrm{I}^{\circ}$.o. Warm area approaching. $\boldsymbol{\Delta} t_{d}=+3^{\circ}$.。.

May 18, r9i6: Low over Finlandia, high on the North Sea. Pressure rising. $\bullet$. Wind E 8. Situation would have implied a dynamic fall in temperature, had not the wind been very strong, and the horizontal differences in temperature small. $\Delta t_{d}=+3 \cdot{ }^{\circ} 8$. 